miles, influenced the officer into a belief of a comparative lack of urgencydoubtless met with to a much lesser degree in the days before radar.

Despite the fact that 'nowadays nearly every vessel carries radar' not every one does; further, a proportion of those which do so have their sets in defective if not unusable condition. Finally, in order to reinforce the views expressed above, it is submitted that the present-day requirement for candidates up for certification only having to 'construe' the Rules, is insufficient. Prior to that edict, it was an absolute requirement for the Rules to be known by heart from start to finish-I can only say that in almost a decade of command time, to say nothing of many years in officer grades, such knowledge was of the greatest value; indeed it introduced a confidence whereby hesitation, indecisiveness and uncertainty were eliminated.

\title{
K's and F's
}

\section{from Duncan M. Henderson (Master Mariner)}

IN the old Cunard Line the log-books on the passenger steamers had a $K$ and an $F$ column on the left-hand page of each opening. This was taken to mean, and in fact was so used, as Knots and Fractions (Nor fathoms as in W. E. May's article, p. I 16, Vol. 27).

Each noon the junior third officer filled in the columns for the previous 24 hours, and each hour had the nautical miles and the fraction thereof expressed in cables which had been steamed, entered in the appropriate box. Thus the figures in the F column never exceeded 9.

I understand from one of the R.N.R. officers who was then in the Company that the R.N. Navigation School (H.M.S. Dryad) has on display a naval log-book of the mid-seventeenth century-with the old K's \& F's columns! Surely it would be easy to check from a few old log-books (from the figures in the F's column) what was originally meant-fathoms or fractions.

To end on a lighter note, there was the apocryphal story in Cunard about the Chief Officer who insisted that the F meant furlongs, and would not permit the Third Officer to put any figure above $\boldsymbol{z}$ in the F column.

\section{Sines, Versines and Haversines in Nautical Astronomy}

\section{Charles H. Cotter}

Op immense importance to nautical astronomers are tables of trigonometrical functions. The history of these begins with the table of chords first suggested by Hipparchus two centuries before the beginning of the Christian Era. The earliest table of chords extant is that computed by Ptolemy (fl. c. I 50 A.D.) whose table, true to the sexagesimal tradition, is based on the division of the radius of a circle 


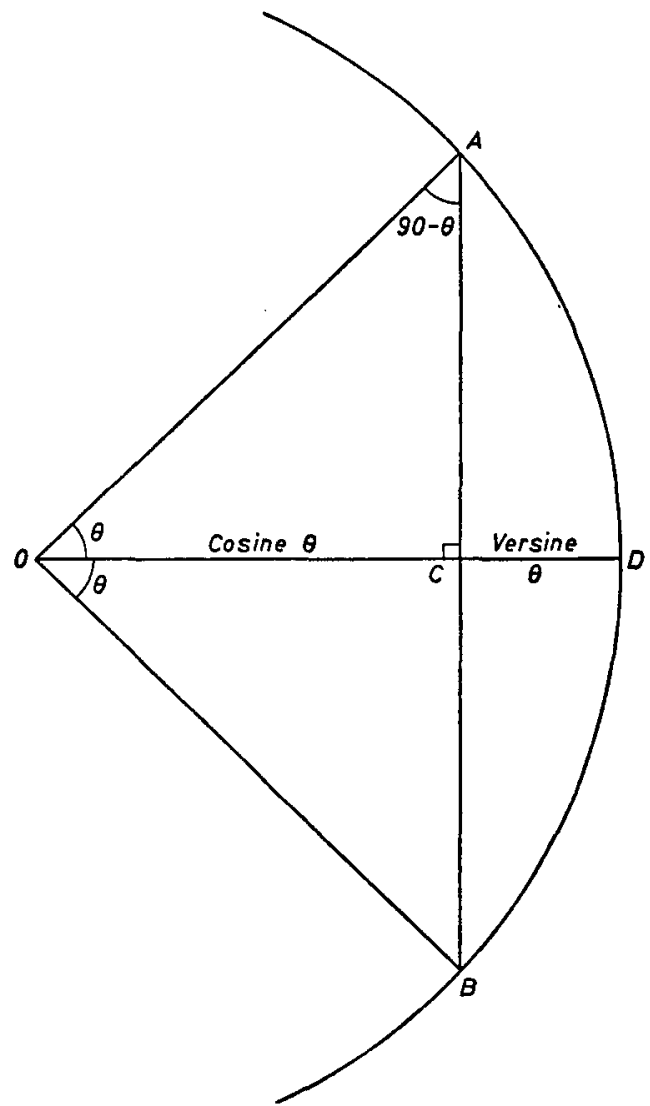

FIG. I

into sixty parts. The first table of half-chords, or sines, is supposed to be of Indian origin and to date from the sixth century; but credit for being first to use a table of half-chords for solving spherical triangles belongs to the Arab mathematician Albategnius who flourished during the tenth century. The first printed table of sines, according to De Morgan, 1 is a small work giving sines to each minute of arc from $0^{\circ}$ to $90^{\circ}$, undated and unsigned but evidently published before 1500 . The evidence suggests that this was produced by Peurbachius (1423-6I) and Regiomontanus $(1436-76)$. The first complete set of tables of the six principal trigonometrical functions (sines, tangents, secants and their reciprocals), forming the trigonometrical canon, was the work of Rheticus (1514-76) whose manuscript tables, on his death, fell into the hands of Pitiscus (156I-16 13 ) who, with great zeal, prepared them for the press.

The first trigonometrical canon to be published in England appeared in Blundevil's Exercises 2 , first issued in 1594. The title page of Blundevil's table announces that it was:

\section{First calculated}

By I. REGIO MONTANVS

But lately examined, and in many places

corrected and amended according to

BARTHO PITISCVS 
According to Blundevil:

' $\ldots$ because that the way to finde out the proportion which any Chord hath to the whole Diameter, was very hard, therefore the said Purbachius and Monte Regio, having directions from certain propositions of Euclid ... they made Choyce of the halfe Chord, and Semidiameter of the Circle, calling the halfe-Chord sinum rectum and the semidiameter sinum totum, and because that the proportion of any Circumference to his Diameter never changeth, how great or how little soever the Circle be; after that they had calculated for one Circle, they made such Tables as might serve for all Circles, by all manner of conclusions ...'

Sinus rectus, or sine of an arc, is defined as the half chord or 'string of an arc', which is double the given arc, and which cuts at right angles that semidiameter which bisects the double arc. In the accompanying diagram, the sine of $\theta$ is the length of half the chord $A B$, which subtends an angle of $2 \theta$ at the centre of the circle of which the arc forms part. The length $\mathrm{CD}$, also a function of $\theta$, is called sinus versus or versine.

Blundevil informs us that sinus versus is called sagitta in Latin which, in English, means a shaft or arrow; for, according to Blundevil:

'.. it is not unlike to the string of a bow ready bent, having a shaft in the middest thereof ...'

The term sinus totus applied to the radius of the circle, the measure of the greatest sine, which is the sine of a quadrant of a circle. The length of $O C$ is the sine of the complement of $\theta$, now called cosine, and the versine of angle $\theta$ is usually defined as $(1-\cos \theta)$.

The existence of tables of trigonometrical functions meant little or nothing to practical seamen of the sixteenth and seventeenth centuries. This is understandable in terms of the tedium and difficulty of solving spherical trigonometrical problems solely by the use of the trigonometrical canon. But this was to change after the invention of logarithms by Napier whose Canon Mirificus appeared in 1614 .

The Elizabethan mathematician Edward Wright, whose work on navigation 3 had considerable impact in the early seventeenth century, was quick to see that Napier's invention could be put to good use by navigators. Accordingly he undertook to translate Napier's work into English specifically for seamen. Before the work was completed Wright died but, at the invitation of Wright's son Samuel, Henry Briggs (who gave us in 1617 the first table of common logarithms) completed the work and prepared it for publication. In the preface to Wright's translation 4 which was published in 1616 , we are informed that Napier had praised Wright and had commended the translation as being conformable to his own mind and to the original work.

Credit for having produced the first table of logarithmic, or artificial, sines and tangents belongs to Edmund Gunter whose work 5 was published in 1620 . Gunter's table comprises 94 pages small octavo, giving logarithmic sines and tangents to seven decimal places at intervals of one minute of arc. It was Gunter's tables that paved the way for the new phase of 'Arithmetical Navigation' for, armed with a logarithmic canon, a navigator who memorized the necessary 'rules' could solve spherical triangles with little or no difficulty.

The impressive work by Sir Jonas Moore, ${ }^{6}$ first published in $168 \mathrm{I}$, is a veri- 
table contemporary encyclopaedia of navigation. An interesting feature of this work is the table of natural and artificial 'versed-sines' which, according to De Morgan, 1 were the first tables of their kind to be printed in England.

The use of versines by practical navigators was encouraged by Joseph de Mendoza Rios who published a set of nautical tables in Spain in I800. In the following year an English edition of the tables appeared. Included in Mendoza Rios' collection are a table of natural versed-sines to six places of decimals at intervals of six seconds of arc, and a table of logarithmic versed-sines at intervals of one minute of arc. In 1805 Mendoza Rios published another set of tables 7 in which he included extended tables of logarithmic versed-sines. In this table he followed the normal plan of tabulating the functions for angles and their complements to $45^{\circ}$ with facilities for reading either from the other. But because this function extends from zero to two, Mendoza Rios gave versines, not only for angles and their complements from $0^{\circ}$ to $45^{\circ}$, but also for the supplements and the complements of the supplements. These four functions were tabulated accordingly as versed-sines, conversed sines, suversed-sines and cosuversed-sines. In a note to the explanation of these tables the author stated:

‘. . What I call here, for the sake of brevity, logarithmic versed- etc., are the logarithms of half the versed-sine etc. . . .'

It follows that Mendoza Rios has given us a table of logarithmic 'half versedsines', or haversines as these are now called.

An interesting work, 8 which appeared in 1805 , was dedicated by its author, James Andrew, to the 'Honourable Court of Directors of the United Company of Merchants of England trading to the East Indies'. This work includes a table, occupying 120 pages, of 'Squares of Natural Semi-Chords'.

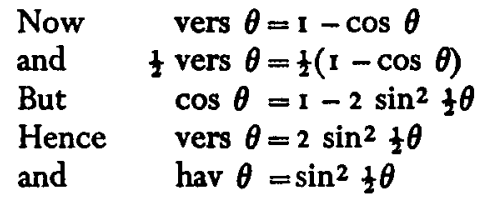

We have seen that the sine of an angle is equivalent to half the chord of twice the angle, so that Andrew's 'Table of Squares of Natural Semi-Chords' is, in fact, a table of natural haversines. It is of interest to note that Andrews' and Mendoza Rios's tables were designed essentially for finding longitude at sea using the lunar method.

The name 'Professor James Inman D.D.' appears in the List of Subscribers to the Second Edition (1809) of Mendoza Rios' Collection of Nautical Tables. This is interesting in that Inman, as we shall see, played a big part in popularizing haversines.

Professor Inman had been Senior Wrangler at Cambridge in 1800 and, before taking up an appointment at the Royal Naval College at Portsmouth, he spent some time at sea on board men-of-war to familiarize himself with navigational methods practised at sea. Later he became well known as an author of navigation textbooks and tables. In his widely-used textbook on nautical astronomy? Inman described the use of versines for solving PZX-triangles in connection with the longitude-by-chronometer method.

The first edition of Inman's Nautical Tables 10 appeared in 1830 . Included in this work are tables of natural versines and half-log-haversines and log-haversines, 
but no logarithmic versines. The name 'Haversine' appears to have been invented by Inman who demonstrated in his book on nautical astronomy how navigational problems could be simplified by the use of logarithmic haversines. In the seventh edition of his textbook published in 1849 Inman introduced a novel method for computing a PZX-triangle for Hour Angle, the rule for which is :

'Under the latitude marked $\mathrm{N}$ or $\mathrm{S}$, put the declination also marked $\mathrm{N}$. or $\mathrm{S}$. If the names be like, take the difference; if the names be unlike take the sum. Under the result put the true zenith distance; take the sum and difference. Add together the log secants of latitude and declination and halves of the log haversines of the sum and difference. With the sum as a log haversine take out the corresponding angle in time'.

The rule, which the practical navigator was expected merely to remember but not necessarily to understand, is based on the formula :

$$
\text { hav } P=\sec \theta \sec d[\text { hav }\{z+(\theta \pm d)\} \text { hav }\{z-(\theta \pm d)\}]^{\frac{1}{2}}
$$

in which $P$ represents the Hour Angle, $\theta$ the latitude, and $d$ and $z$ the body's declination and zenith distance respectively.

Inman's Tables were adopted by the Royal Navy and his method of solving a PZX-triangle was the standard method used in that service right up to the beginning of the present century.

The fundamental formula for solving a spherical triangle given three sides to find an angle, or for finding a side given the opposite angle and the other two sides, is the spherical cosine rule. Because this rule is unsuitable for logarithmic computation, numerous formulae (including Inman's formula described above) have been derived from it, and a multitude of derived formulae have been taught to seamen down the ages. It was not until the beginning of the present century that nautical astronomical instruction was standardized, largely through the influence of Royal Naval Navigation Schools, and the cosine-haversine formula since that time has been taught almost to the complete exclusion of other directmethod alternatives for the solution of PZX-triangles. The cosine-haversine rule, which is readily derived from the cosine rule, is :

$$
\text { hav } P=\{\text { hav } z-\operatorname{hav}(\theta \pm d)\} \sec \theta \sec d
$$

or:

$$
\text { hav } z=\text { hav }(\theta \pm d)+\text { hav } P \cos \theta \cos d
$$

By multiplying through by 2 , these formulae become, respectively:

and

$$
\text { vers } P=\{\text { vers } z-\text { vers }(\theta \pm d)\} \sec \theta \sec d
$$

$$
\text { vers } z=\operatorname{vers}(\theta \pm d)+\operatorname{vers} P \cos \theta \cos d
$$

The second of these formulae was introduced by Regiomontanus 11 in the sixteenth century long before seamen ever dreamed of having to solve spherical triangles; and, indeed, it was not until I 899 that the Royal Naval Instructor H. B. Goodwin proposed its use (having derived the formula independently of Regiomontanus) for nautical astronomical and great circle sailing purposes. In his paper 12 Goodwin pointed out that:

'... since in Inman we have no logarithmic versines but only log-haversines, we must divide each side by two ....' 
In the same paper Goodwin described the advantages of a table giving natural and logarithmic haversines set down, for each tabulated angle, abreast of each other. It is evident that Goodwin was not aware that this technique had been used for versines, as well as for other trigonometrical functions, by Henry Sherwin 13 as early as 1705 . The juxtaposition of natural and logarithmic haversines may seem a small matter, but it greatly facilitates the computation of spherical triangles using the cosine-haversine rule, and Goodwin is to be admired for having suggested it.

Percy L. H. Davis, in his Requisite Tables 14 first published in 1905, gave a table of natural and logarithmic haversines along the lines suggested by Goodwin. A similar table was soon to appear in most of the popular collections of nautical tables; and this, in some instances, was a source of extreme annoyance to Davis who was evidently very jealous of his copyright to the table. The widespread availability of the new haversine table led to standardization of sight reduction, and the standard method, in which the cosine-haversine rule is employed, is still widely used.

It is interesting that such a neat formula as the cosine-versine rule, introduced by Regiomontanus as far back as the fifteenth century, was never adopted by practical navigators until comparatively recent times, and even then only in a somewhat disfigured form. The artificial function hoversine appears to have been adopted instead of the natural function versine merely because the popular Inman collection of nautical tables, used by Royal Naval Officers at the end of the nineteenth century, did not contain a table of logarithmic versines.

\section{REFEREN CES}

1 De Morgan, A. (1861). Tables, The English Cyclopaedia, London.

2 Blundevil, T. (1 594). His Exercises, contayning Eight Treatises ... London. Seventh edition 'corrected and somewhat enlarged' by R. Hartwell, London, 1636 .

3 Wright, E. (1599). Certain Errors in Navigation detected and corrected . . . London.

4 Wright, E. (1616 Posthumous). A Duscription of the Admirable Table of Logarithms, London.

$s$ Gunter, E. (1620). Canon Triangulorum sive Tabulae Sinuum et Tangentium Artificialum, London.

6 Moore, Sir. J. (1681). A New Systeme of the Mathematics, London.

7 De Mendoza Rios, J. (1805). A Complete Collection of Tables for Navigation and Nautical Astronomy, London.

8 Andrews, J. (1805). Astronomical and Nautical Tables, London.

9 Inman, J. (1821). Narigation and Nautical Astronomy for the Use of British Seamen,

Portsmouth. (Second edition, 1826; Third edition, 1835; Seventh edition, 1849.)

10 Inman, J. (1830). Nautical Tables Designed for the Use of British Seamen, London.

11 Muller, J. (Regiomontanus) (1533). De triangulis omniodis. Translated by Barnabus Hughes, O.F.M. (1967), London.

12 Goodwin, H. B. (1899). The Simplification of Formulae in Nautical Astronomy. The Nautical Magazine, Volume 68, Glasgow.

13 Sherwin, H. (1705). Mathematical Tables, London.

14 Davis, P. L. H. (1905). Requisite Tables, London. 